\title{
RUMO A UMA FRATERNIDADE DE CORTES DE DIREITOS HUMANOS? UMA ANÁLISE DOS USOS DA JURISPRUDÊNCIA DA CORTE EUROPEIA PELA CORTE INTERAMERICANA DE DIREITOS HUMANOS ${ }^{1}$.
}

\author{
TOWARDS A FRATERNITY OF HUMAN RIGHTS \\ COURTS? ASSESSING THE USES OF THE \\ EUROPEAN COURT'S CASE LAW BY THE INTER- \\ AMERICAN COURT.
}

Fabia Fernandes Carvalho Veçoso

Recebido em: 29/09/2013

Sumário: I. Introdução. II. A jurisprudência da CIDH em matéria de anistias internas. III. A jurisprudência da CIDH em matéria de liberdade de expressão. IV. Considerações finais. Referências Bibliográficas.

Resumo:

$\mathrm{O}$ artigo possui como objetivo analisar os usos da jurisprudência da Corte Europeia de Direitos Humanos pela Corte Interamericana de Direitos Humanos. Para tanto, dois grupos de decisões serão estudados, o primeiro relacionado as anistias domésticas, tema de intensa atividade pela Corte Interamericana, e o segundo relacionado à liberdade de expressão, um tradicional tópico europeu. A pesquisa revela que o almejado movimento progressivo no sentido de uma uniformização da interpretação do corpus iuris do direito
Abstract

The article aims at analyzing the uses of the European Court of Human Rights case law by the Inter-American Court of Human Rights. For this end, two groups of decisions will be assessed, one related to domestic amnesties, a matter of intense adjudication by the Inter-American Court, and the other related to freedom of expression, a traditional European topic. The analysis shows that the intended progressive movement towards an uniform interpretation of the corpus iuris of international buman rights law seems to give way to institutional interests and political choices undertaken by courts.

1 Uma versão preliminar deste trabalho foi apresentada na 2a Conferência Bienal da Sociedade LatinoAmericana de Direito Internacional, realizada entre 23 e 25 de agosto de 2012, no Rio de Janeiro. Programa completo da conferência disponível em: <http://lasil-sladi.org/files/live/sites/lasil-sladi/files/shared/ Rio\%202012/SLADI\%20II\%20Conferencia\%20Programa\%20_\%20Final.pdf>. Acesso em: 20 Set. 2013. 
internacional dos direitos humanos parece ceder espaço para interesses institucionais e escolhas políticas que são empreendidas pelas cortes.

Palavras-chave:

Diálogo entre cortes; Fertilização cruzada;

Direito Internacional dos Direitos Humanos.
Keywords:

Dialogue between courts; Cross-fertilization;

International human rights law.

\section{Introdução}

Desde seus primeiros anos de atividade, a Corte Interamericana de Direitos Humanos (corte ou CIDH) tem articulado a jurisprudência do órgão jurisdicional correspondente na Europa, a Corte Europeia de Direitos Humanos $(\mathrm{CEDH})$, buscando elaborar o seu próprio conjunto de decisões em matéria de direitos humanos. No caso Velásquez-Rodríguez, o primeiro caso com decisão de mérito da CIDH relativamente à sua jurisdição contenciosa, a corte determinou que "A indenização por violação de direitos humanos encontra fundamento em instrumentos internacionais de caráter universal e regional. (...) O mesmo foi feito pela Corte Europeia de Direitos Humanos com base no artigo 50 da Convenção para Proteção dos Direitos do Homem e Liberdades Fundamentais." (CIDH, 1989, par. 28) (Tradução nossa). ${ }^{2}$ Nesse caso, a menção à jurisprudência da CEDH teve como objetivo sublinhar a competência da CIDH para determinar o pagamento de indenizações diante das violações verificadas no caso Velásquez:

Em sua atividade de interpretação dos dispositivos da Convenção Americana de Direitos Humanos (convenção), a corte faz constante referência aos casos apreciados pela $\mathrm{CEDH}$, como se a última pudesse ser vista como sua "irmã mais velha", 3 ambas interagindo em um processo que tem sido referido como "fertilização

2 "La indemnización por violación de los derechos humanos encuentra fundamento en instrumentos internacionales de carácter universal y regional. (...) Lo propio ha hecho la Corte Europea de Derechos Humanos con base en el artículo 50 de la Convención para la Protección de los Derechos Humanos y de las Libertades Fundamentales."

3 Como afirma Antônio Augusto Cançado Trindade (2006, p. 354): "Malgré les différences entre les réalités propres aux deux continents sur lesquels elles déploient leurs activités, les Cours Européenne et Interaméricaine des Droits de l'Homme ont des jurisprudences qui présentent des rapprochements et des convergences. La façon d'aborder les questions fondamentales d'interprétation et d'application des deux Conventions régionales des droits de l'homme est un bon exemple de la convergence des points de vue. Je considère la riche jurisprudence sur les méthodes d'interprétation de la Convention Européenne comme une contribution majeure de la Cour Européenne au Droit International des Droits de l'Homme dans son ensemble. Sa jeune soeur, la Cour Interaméricaine, a également eu l'occasion, lors du règlement d'affaires qui reflétaient les réalités des droits de l'homme sur le continent américain, de constituer sa propre jurisprudence sur les méthodes d'interprétation de la Convention Américaine, faisant ainsi apparaittre, comme je l'ai indiqué, une convergence rassurante avec la jurisprudence de la Cour Européenne." 
cruzada" entre a jurisprudência das duas instâncias jurisdicionais regionais de direitos humanos. ${ }^{4}$ Nesse sentido, essa interação permitiria uma interpretação uniforme do corpus iuris em desenvolvimento relacionado ao direito internacional dos direitos humanos, proporcionando a imposição de limites ao voluntarismo estatal, o fortalecimento da proteção aos direitos humanos, além de garantir o status de sujeito de direito internacional aos indivíduos (TRINDADE, 2006, p. 361).

O presente artigo possui como objetivo analisar esse diálogo entre a jurisprudência da Corte Europeia e a jurisprudência da Corte Interamericana, elencando como foco a importação de interpretações europeias pela CIDH fluxo apontado com mais intenso do que o uso de decisões da CIDH pela sua correspondente europeia (HENNEBEL, 2007, p. 16-31; TRINDADE, 2006, p. 361). Busca-se, assim, fomentar o debate a respeito dos diferentes usos dos julgados da CEDH pela corte.

O argumento a ser desenvolvido neste trabalho pressupõe que, para além de um processo mecânico ou descomplicado de aplicação dos precedentes europeus pela CIDH, a corte importa interpretações europeias de uma maneira estratégica, seguindo uma racionalidade específica ao decidir casos concretos. Em outras palavras, a corte faz sua própria leitura dos precedentes europeus, conforme os contornos do caso que deve decidir.

Ademais, a importação de decisões da CEDH é feita para legitimar a própria atuação da $\mathrm{CIDH}$, como se os precedentes europeus pudessem conferir persuasão, legitimidade e autoridade às decisões da corte (HENNEBEL, 2007, p. 26), especialmente diante do frágil consenso regional relacionado à sua atuação no continente (NEUMAN, 2008, p. 101). Neste passo, o argumento a ser desenvolvido busca desafiar o entendimento que afirma a possibilidade de uma interpretação uniforme do direito internacional dos direitos humanos por meio da "fertilização cruzada" entre a jurisprudência das duas cortes regionais.

O que se pretende salientar é a complexidade nos usos dos julgados europeus pela CIDH, isto é, a chamada "fertilização cruzada" não teria como resultado certo e garantido a uniformização da jurisprudência internacional em matéria de direitos humanos. Não que seja possível negar o fato de que as cortes dialogam, mas a questão importante é que esse diálogo não ocorre de forma neutra e desinteressada, como se a uniformização da interpretação relacionada ao direito internacional dos

4 Como afirma Ludovic Hennebel (2007, p. 1), "La technique des références croisées consiste pour un juge à se référer à un instrument ou à une jurisprudence qui lui est étranger.” Anne-Marie Slaughter, em artigo mais antigo, buscou compreender o fenômeno que denominou transjudicial communication, isto é, os diálogos que se estabelecem entre cortes para além das fronteiras nacionais. Segundo a autora, "The geometry of transjudicial communication varies according to the national or supranational status of such communication: horizontal, vertical, and mixed vertical-horizontal. A related difference flows from the relative status of courts in a national or supranational hierarchy." (SLAUGHTER, 1994, p. 103) 
direitos humanos fosse uma consequência natural desse processo de referências cruzadas. Os pressupostos políticos relacionados à atuação da CIDH interferem de forma substantiva na maneira como a mesma utiliza julgados da CEDH. Assim, esse processo de "fertilização cruzada" constitui-se como processo complexo, composto por várias facetas, as quais não tenderiam necessariamente à uma uniformização dos entendimentos relacionados à proteção internacional da pessoa humana.

Este artigo inspira-se nos trabalhos de Gerald L. Neuman (2005; 2008), os quais salientam os vários fluxos possíveis na construção da jurisprudência interamericana. Além de importar julgados europeus, a CIDH também busca exportar seus próprios entendimentos, com o objetivo de legitimar sua atuação, declarando expressamente sua contribuição para o desenvolvimento do direito internacional dos direitos humanos e também para o direito internacional em geral. ${ }^{5}$ Aqui vale mencionar, de forma ilustrativa, o interesse da corte em identificar normas de jus cogens, em temas como proibição da escravidão, tortura, desaparecimento forçado, execução extrajudicial, discriminação, crimes contra humanidade, acesso à justiça, dentre outros (NEUMAN, 2008, p. 118).

Para debater os diferentes usos da jurisprudência europeia pela CIDH, dois grupos temáticos de decisões da corte foram selecionados para análise neste trabalho, sempre com relação à sua competência contenciosa. O primeiro se relaciona à validade de leis de anistia dos Estados partes, assunto de intensa atividade jurisdicional da $\mathrm{CIDH}$, e o segundo grupo se relaciona à liberdade de expressão, matéria tradicionalmente abordada pela CEDH.

Conclui-se, ao final, que a análise da importação de precedentes europeus pela CIDH contribui para colocar luz na complexidade envolvida na interpretação das regras internacionais de direitos humanos, assim como traz à tona as perspectivas específicas ou vieses de instituições internacionais como a CIDH. O pretendido movimento progressivo no sentido de uma uniformização da interpretação do corpus iuris do direito internacional dos direitos humanos parece ceder espaço para usos estratégicos de julgados internacionais, usos que seguem interesses institucionais e escolhas políticas realizadas pelas cortes regionais de proteção aos direitos humanos.

5 Como afirma Neuman (2008, p. 116), “The Inter-American Court is not, of course, merely a passive importer of human rights interpretations. Even as an importer, the Court is selective, but the Court also engages in innovative interpretations of its own, sometimes specifically based in regional realities, and sometimes based on universalist considerations. The Court aspires to be an exporter of human rights interpretations." 


\section{A jurisprudência da CIDH em matéria de anistias internas}

Quatro casos relacionados a leis de anistias internas foram analisados pela CIDH. ${ }^{6}$ Trata-se dos casos Barrios Altos Vs. Peru (CIDH, 2001a, 2001b, 2001c), Almonacid-Arellano et al. Vs. Chile (CIDH, 2006a), Gomes Lund et al. Vs. Brasil (CIDH, 2010a) e Gelman Vs. Uruguay (CIDH, 2011). De uma forma geral, situações de violação aos direitos previstos na Convenção Americana foram levadas à corte para que se analisasse a responsabilidade dos Estados-partes pela sua ocorrência. Em virtude da vigência de leis de anistia locais, adotadas no âmbito dos processos de transição de regimes autoritários nos quatro países em questão, as violações alegadas não foram investigadas nem julgadas. Na ausência de julgamentos, a Corte Interamericana analisou os casos concretos afirmando que os referidos Estadospartes são responsáveis, perante a Convenção Americana, pelas violações de direitos humanos ocorridas durante os correspondentes regimes autoritários nacionais.

Segundo a corte, leis de anistia são contrárias ao direito internacional por força de um inequívoco dever estatal de julgar violações de direitos humanos. Assim, nos termos do entendimento afirmado pela CIDH, violações de direitos humanos relacionadas aos contextos de transição política na América Latina devem ensejar necessariamente a realização de julgamentos. Seguindo a argumentação do órgão, essa preferência por julgamentos é revestida de um discurso universalista, afirmando-se o caráter imperativo das regras de direito internacional de direitos humanos violadas pelos Estados nos casos concretos.

O presente trabalho não possui como objetivo empreender uma análise aprofundada do posicionamento da CIDH relativamente às leis de anistia adotadas por Estados partes na convenção, ${ }^{7}$ mas sim debater o uso de julgados europeus pela corte para o desenvolvimento de sua jurisprudência em matéria de anistias na América Latina. Vale somente sublinhar que a corte estabeleceu um posicionamento

\footnotetext{
Considerando o alcance do presente artigo, não será analisada a recente decisão da CIDH no caso El Mozote. Esse caso discute a compatibilidade entre a anistia salvadorenha "Lei de Anistia Geral para a Consolidação da Paz", aprovada pela Assembleia Legisllativa da República de El Salvador, em 1993, e a Convenção Americana de Direitos Humanos. A análise da corte sobre a anistia salvadorenha é focada no direito internacional humanitário, e mesmo constituindo-se como julgado importante na jurisprudência da CIDH em matéria de anistias, sua discussão extrapola o escopo deste artigo. Nesse sentido, "However, contrary to the cases examined previously by this Court, the instant case deals with a general amnesty law that relates to acts committed in the context of an internal armed conflict. Therefore, the Court finds it pertinent, when analyzing the compatibility of the Law of General Amnesty for the Consolidation of Peace with the international obligations arising from the American Convention and its application to the case of the Massacres of El Mozote and Nearby Places, to do so also in light of the provisions of Protocol II Additional to the 1949 Geneva Conventions, as well as of the specific terms in which it was agreed to end hostilities, which put an end to the conflict in El Salvador and, in particular, of Chapter I ("Armed Forces"), section 5 ("End to impunity"), of the Peace Accord of January 16, 1992." (CIDH, 2012, par. 284).

7 Para essa análise, ver VEÇOSO, Fabia Fernandes Carvalho; AMARAL JR., Alberto do. The Inter-American System as New Grossraum? Assessing the Case Law of the Inter-American Court of Human Rights. European Society of International Law 2011 4th Research Forum, maio 2011. Disponível em SSRN: <http:/ / ssrn. com/abstract=1967666>. Acesso em: 19 Set. 2013.
} 
relevante no que tange aos processos de justiça de transição empreendidos pelo Peru, Chile, Brasil e Uruguai, negando efeitos jurídicos às anistias adotadas pelos mencionados Estados-partes e determinando a realização de investigações e julgamentos relacionados às violações nos casos Barrios Altos, Almonacid, Gomes Lund e Gelman.

Inicialmente, vale afirmar que a importação de julgados europeus pela CIDH nos casos relacionados às anistias dos Estados partes não possui apenas uma única racionalidade. Em muitas dessas ocorrências de importação, a CIDH refere a jurisprudência europeia como argumento de autoridade, o que teria o condão de conferir legitimidade às decisões da $\mathrm{CIDH}$ diante da ausência de jurisprudência interamericana em algumas matérias. Mesmo no caso em que há jurisprudência interamericana, a menção aos julgados europeus busca conferir persuasão à interpretação da $\mathrm{CIDH}$, tendo em vista a alegada convergência de entendimentos com sua "irmã mais velha".

Para a hipótese de importação enquanto argumento de autoridade, deve-se referir as menções aos julgados europeus feitas nos casos Gomes Lund e Gelman. No primeiro, menções à interpretação europeia ocorrem em três pontos distintos da decisão: i) quando referido o caráter pluriofensivo e continuado do desaparecimento forçado, em que a jurisprudência europeia é citada como correspondente ao entendimento da CIDH na matéria - entendimento interamericano que é anterior ao entendimento europeu, frise-se (CIDH, 2010a, par. 104); ${ }^{8}$ ii) relativamente à noção de "recurso efetivo" em casos de violação do direito à vida ou integridade pessoal, tendo sido afirmado pela CIDH a necessidade de conduzir investigação exaustiva e eficaz nesses casos de violação, além do pagamento de indenizações aqui os julgados europeus norteariam o entendimento de "recurso efetivo" (CIDH, 2010a, par. 145) e iii) quando referida a imprescritibilidade de processos penais referentes a graves violações de direitos humanos, sendo igualmente vedada, nesses casos, a concessão de anistias ou perdões (CIDH, 2010a, par. 161). ${ }^{10}$

8 A nota de rodapé 127 na decisão do caso Gomes Lund menciona as seguintes decisões da CEDH: Caso Kurt v. Turquia, application No. 15/1997/799/1002, julgamento de 25 de Maio de 1998, parágrafos 124 a 128; Caso Cakici v. Turquia, application No. 23657/94, julgamento de 8 de Julho de 1999, parágrafos 104 a 106; Caso Timurtas v. Turquia, application No. 23531/94, julgamento de 13 de Junho de 2000, parágrafos 102 a 105; Caso Tas v. Turquia, application No. 24396/94, julgamento de 14 de novembro de 2000, parágrafos 84 a 87, e Caso Cyprus v. Turquia, application No. 25781/94, Julgamento de 10 de Maio de 2001, parágrafos 132 a 134 e 147 a 148.

9 A nota de rodapé 195 na decisão do caso Gomes Lund menciona as seguintes decisões da CEDH: Caso Aksoy v. Turquia, application No. 21987/93, julgamento de 18 de Dezembro de 1996, parágrafo 98; Caso Aydin v. Turquia, application No. 23178/94, julgamento de 25 de Setembro de 1997, parágrafo 103; Caso Selçk and Asker v. Turquia, applications Nos. 23184/94 e 23185/94, julgamento de 24 de Abril de 1998, parágrafo 96, e Caso Keenan v. Reino Unido, application No. 27229/95, julgamento de 3 de Abril de 2001, parágrafo 123.

10 A nota de rodapé 220 na decisão do caso Gomes Lund menciona a seguinte decisão da CEDH: Caso Abdülsamet Yaman v. Turquia, application No. 32446/96, julgamento de 2 de Novembro de 2004, parágrafo 55. Vale sublinhar que esse julgado europeu, datado de 2004, é posterior ao primeiro julgado da CIDH em matéria de anistias, o caso Barrios Altos, de 2001. 
No caso Gelman, há também três menções a julgados europeus na decisão da CIDH. A primeira também trata do caráter pluriofensivo e continuado do desaparecimento forçado, sendo citados os mesmos precedentes europeus constantes no caso Gomes Lund (CIDH, 2011, par. 65, nota de rodapé 66). A segunda menção trata do direito ao nome, reconhecido no artigo 18 da convenção. Aqui a corte cita casos da CEDH para buscar fortalecer a tutela a esse direito, afirmando o seu amplo reconhecimento internacional (CIDH, 2011, par. 127). ${ }^{11}$ Finalmente, a terceira menção também diz respeito à imprescritibilidade de processos penais relacionados a graves violações de direitos humanos, da mesma forma como visto no caso Gomes Lund e com o mesmo caso europeu citado (CIDH, 2011, par. 213, nota de rodapé 260).

No caso Barrios Altos, primeiro julgado da CIDH que determinou a invalidade de leis de anistia de um Estado parte, não houve menção à jurisprudência europeia. Aqui a corte parece ter inaugurado um posicionamento jurisprudencial em âmbito internacional, no sentido de afirmar a contrariedade das anistias em relação ao disposto pelo direito internacional. ${ }^{12}$

$\mathrm{O}$ uso mais interessante de julgados europeus na jurisprudência da CIDH sobre leis de anistia foi feito no caso Almonacid (CIDH, 2006a). Nesse, as duas menções às decisões da $\mathrm{CEDH}$ se relacionam à aos esforços argumentativos da CIDH para caracterizar a morte da vítima, senhor Almonacid Arellano, como crime contra a humanidade. O senhor Almonacid foi morto por agentes da polícia chilena em 1973, início do regime Pinochet, e o Chile reconheceu a competência da corte somente para fatos cujo princípio de execução tenha se verificado após 11 de março de 1990.

A corte afastou a exceção preliminar apontada pelo Chile relativamente à sua competência ratione temporis e declarou-se competente para se pronunciar sobre as violações em debate, acatando o posicionamento da Comissão Interamericana de Direitos Humanos (comissão) de que o caso compreenderia violações autônomas de direitos humanos, verificadas após 1990 - ainda que relacionadas à morte do senhor Almonacid de 1973.

Neste passo, seguindo a argumentação da comissão, a anistia adotada pelo Chile em 1978 (decreto-lei n. 2.191/78) continuou em vigor após 1990, fato que violaria

11 A nota de rodapé 142 na decisão do caso Gelman menciona as seguintes decisões da CEDH: Caso Stjerna v. Finland, application No. 18131/91, julgamento de 25 de Novembro de 1994, parágrafo 37 e Caso Burghartz v. Switzerland, application No. 16213/90, julgamento de 22 de Fevereiro de 1994, parágrafo 24.

12 No entanto, esse posicionamento da CIDH relativamente à invalidade de anistias domésticas perante o direito internacional não seria algo inédito. Desenvolvido no âmbito das Nações Unidas, o discurso relacionado à chamada luta contra a impunidade aparece fortemente na atuação da ONU desde os anos 90, valendo mencionar, a título ilustrativo, os Joinet Principles, relatório elaborado pelo special rapporteur Louis Joinet sobre o combate à impunidade de violações de direitos civis e políticos (ORGANIZAÇÃO DAS NAÇÕES UNIDAS, 1997) 
a Convenção Americana, na medida em que a anistia chilena impediu a investigação do caso e julgamento dos responsáveis pela morte do senhor Almonacid. A anistia foi aplicada pelas autoridades militares, as quais foram declaradas competentes para investigar o caso em âmbito interno.

Para analisar as referidas violações, a $\mathrm{CIDH}$ seguiu os seguintes etapas argumentativas: a) discutir a qualificação da morte do senhor Almonacid como crime contra a humanidade; b) em caso afirmativo, discutir se tal crime poderia ser anistiado; c) em caso negativo, discutir se o decreto-lei n. 2.191/78 previu uma anistia para o crime e se o Chile violaria a convenção ao manter vigente essa decretolei; e d) discutir se a aplicação dessa lei pelo judiciário chileno violaria dispositivos da Convenção Americana.

Quanto à análise de fatos anteriores ao reconhecimento de competência da corte pelo Chile, isto é, fatos anteriores a 1990, afirmou a CIDH: "[...] Por outro lado, a Corte deseja enfatizar que os fatos descritos na alínea b) infra, relativos ao ocorrido anteriormente à data de ratificação da competência da corte por parte de Chile, unicamente servem como antecedentes para contextualizar os fatos assinalados nas alíneas seguintes.” (CIDH, 2006a, par. 82) (Tradução nossa). ${ }^{13}$

A corte justificou sua abordagem mencionando um julgado da $\mathrm{CEDH}$, o caso Broniowski vs. Poland. ${ }^{14}$ Segundo a CEDH, mesmo que existam limites temporais para o exercício de suas atividades, fatos ocorridos antes da ratificação da Convenção Europeia poderiam ser considerados, desde que relevantes para a compreensão do ocorrido após a ratificação da Convenção Europeia ou desde que tenham criado uma situação que se perpetue no tempo. ${ }^{15}$

13 “[...] Por otro lado, la Corte desea precisar que los hechos descritos en el literal b) infra, relativos a lo ocurrido con anterioridad a la fecha de ratificación de la competencia de la Corte por parte de Chile, únicamente sirven como antecedentes para contextualizar los hechos señalados en los literales siguientes."

14 Nesse caso, a CEDH determinou compensações coletivas retroativas para violações que ocorreram antes da criação da corte, entre os anos 1940 e 1950 - a CEDH iniciou suas atividades em 1959 (CEDH, 2004; 2002).

15 Em decisão proferida sobre a admissibilidade do caso, a CEDH se manifestou expressamente sobre sua competência ratione temporis, afirmando o caráter continuado da situação de violação de direitos humanos: "The Court's jurisdiction ratione temporis covers only the period after the ratification of the Convention or its Protocols by the respondent State. From the ratification date onwards, all the State's alleged acts and omissions must conform to the Convention or its Protocols and subsequent facts fall within the Court's jurisdiction even where they are merely extensions of an already existing situation (see, for example, Yağci and Sargin v. Turkey, judgment of 8 June 1995, Series A no. 319-A, p. 16, \ 40, and Almeida Garrett, Mascarenhas Falcão and Others v. Portugal, nos. 29813/96 and 30229/96, J 43, ECHR 2000-I). Accordingly, the Court is competent to examine the facts of the present case for their compatibility with the Convention only in so far as they occurred after 10 October 1994, the date of ratification of Protocol No. 1 by Poland. It may, however, have regard to the facts prior to ratification inasmuch as they could be considered to have created a situation extending beyond that date or may be relevant for the understanding of facts occurring after that date. [...] In so far as the applicant's complaints are directed against the acts and omissions of the Polish State in relation to the implementation of an entitlement to a compensatory measure vested in him under Polish law, an entitlement which continued to exist after 10 October 1994 and still exists today, the Court has temporal jurisdiction to entertain the application." (CEDH, 2002, paras. 74-77). 
Ademais, a CEDH manifestou-se expressamente sobre os limites de sua atuação tendo em vista o contexto histórico do caso $^{16}$ - posicionamento que a $\mathrm{CIDH}$ parece ter desconsiderado em sua estratégia argumentativa desenvolvida no caso Almonacid Arellano. Primeiramente, considerar a morte do senhor Almonacid uma violação continuada de direitos humanos seria uma argumentação frágil da $\mathrm{CIDH}$, posto que não se trata de situação com efeitos que se perpetuam no tempo. Ademais, o Chile estabeleceu um limite temporal claro para a competência da corte: para fatos verificados a partir de 11 de março de 1990. Diferentemente de uma violação continuada como o desaparecimento forçado, o caso Almonacid Arellano envolveu a execução ilegal de um civil por agentes estatais chilenos, ato localizado no tempo de maneira determinada.

Asim, para garantir a competência da corte no caso Almonacid, foi afirmada a existência de violações autônomas de direitos humanos após a morte do senhor Almonacid, na época em que a corte já possuía competência para julgar o Chile (após 11 de março de 1990).

A possibilidade de considerar fatos anteriores à ratificação da Convenção Americana não foi desprezada pela CIDH e o precedente europeu foi utilizado justamente para embasar essa análise de fatos anteriores a 1990, ou seja, a morte do senhor Almonacid em 1973. Seguindo os termos da interpretação europeia constante no caso Broniowski, a CIDH afirmou que fatos do passado podem ser considerados desde que relevantes para esclarecer a situação de violação em análise, no sentido de empreender uma completa narrativa da questão fática relacionada à demanda, com o propósito de contextualização (CIDH, 2006a, par. 82).

No entanto, uma narrativa fática completa é algo bem distinto da qualificação jurídica de fatos - ou seja, qualificar a morte do senhor Almonacid como crime contra a humanidade. Frise-se: fato que a corte expressamente excluiu de sua competência no presente caso.

Pode-se afirmar, assim, que a CIDH construiu sua argumentação a partir de uma interpretação específica do julgado europeu, sem considerar as limitações impostas pela própria $\mathrm{CEDH}$ à sua atuação relativamente ao contexto histórico do

16 Afirmou a CEDH: "While the historical background of the case, including the post-war delimitations of State borders, the resultant migration of persons affected by those events and the Republican Agreements, in which the applicant's entitlement to compensation originated (see paragraphs 10-12, 39-41, 67 and 81 above), is certainly important for the understanding of the complex legal and factual situation obtaining today, the Court will not consider any legal, moral, social, financial or other obligations of the Polish State arising from the fact that owners of property beyond the Bug River were dispossessed and forced to migrate by the Soviet Union after the Second World War. In particular, it will not deal with the issue whether Poland's obligation under the Republican Agreements to return to those persons the value of the property abandoned in the former Soviet republics might have any bearing on the scope of the applicant's right under domestic legislation and under the Convention and whether Poland honoured the obligations it had taken upon itself by virtue of those Agreements." (CEDH, 2004, par. 124) (Grifou-se). 
caso Broniowski. A CIDH, para além do propósito de contextualização, qualificou a morte do senhor Almonacid como crime contra a humanidade. E essa qualificação foi absolutamente fundamental para determinar a invalidade da anistia chilena diante dos dispositivos da Convenção Americana, eis que crimes contra a humanidade seriam imprescritíveis.

Para garantir sua competência ratione temporis no caso, a $\mathrm{CIDH}$ fez uso estratégico do precedente europeu, alegando que: a) sim, a morte em questão constitui crime contra a humanidade; b) crimes contra a humanidade são imprescritíveis e, portanto, não podem ser anistiados; c) sim, o decreto-lei n. 2.191/78 previu uma anistia para o crime em questão, e o Chile viola a convenção ao manter vigente essa decreto-lei após tê-la ratificado; e d) sim, houve aplicação do decreto-lei durante o processo interno de investigação da morte do senhor Almonacid e essa aplicação viola os direitos previstos na convenção (CIDH, 2006a, par. 93-129).

Esse esquema argumentativo gerou a responsabilização do Chile e a declaração de que o decreto-lei n. 2.191/78 não possui efeitos jurídicos.

Por fim, a segunda menção à jurisprudência da $\mathrm{CEDH}$ no caso Almonacid se relaciona à proibição de cometer crimes contra a humanidade enquanto regra internacional de jus cogens, de forma que a punição a tais crimes seria obrigatória para o direito internacional geral (CIDH, 2006a, par. 99). Aqui a CIDH cita o precedente europeu Kolk y Kislyiy v. Estonia (CIDH, 2006a, par. 100), ${ }^{17}$ julgado em 2006, no qual alegou-se que os senhores Kolk e Kislyiy cometeram crimes contra a humanidade em 1949, sendo julgados e condenados por cortes nacionais na Estônia entre 2003 e 2004. A CEDH reafirmou o posicionamento do judiciário daquele país, determinando que, mesmo se os atos cometidos pelos autores (deportação de civis para territórios remotos da União Soviética) pudessem ser considerados legais em 1949 (vigente à época o código criminal soviético de 1946, aplicável à Estônia enquanto república socialista soviética), tais atos devem ser considerados crimes contra a humanidade, em conformidade com o disposto pelo direito internacional já em 1949 (CIDH, 2006a, par. 100). Em outras palavras, à época, atos de deportação já seriam criminalizados pelo direito internacional, sendo necessária a sua punição e não havendo, portanto, aplicação retroativa de normas penais. ${ }^{18}$

17 Na nota de rodapé 126, a CIDH cita o Caso Kolk and Kislyiy v. Estonia, julgamento de 17 de Janeiro de 2006, applications Nos. 23052/04 e 24018/04.

18 Sobre o caso Kolk y Kislyiy v. Estonia, ver CASSESE, Antonio. Balancing the prosecution of crimes against humanity and non-retroactivity of criminal law. European Journal of International Law, Oxford, v. 4, n. 2, p. 410-418, 2006 e GROVER, Sonja C. The European Court of Human Rights as a Pathway to Impunity for International Crimes. Heidelberg: Springer, 2010, p. 230-236. 
O objetivo da CIDH ao mencionar o precedente europeu sobre crimes contra humanidade é legitimar sua atuação ao qualificar juridicamente o morte do senhor Almonacid enquanto tal, afirmando que em 1973 já haveria consenso internacional relativamente ao caráter imperativo da norma que proíbe o cometimento de tais crimes. $^{19}$

Diante do exposto, pode-se ressaltar a utilização estratégica da jurisprudência europeia pela CIDH nos casos relacionados às leis de anistias dos Estados-partes. Sublinhe-se que tal utilização possui diversas racionalidades e quem nem sempre a CIDH cita precedentes europeus de forma mecânica. A corte busca construir sua própria argumentação a partir das interpretações europeias, o que pode ser visto no caso Almonacid relativamente ao uso do julgado Bronionski, sem que seja possível garantir, em todos os casos de referências cruzadas, uma convergência entre a jurisprudência das duas cortes regionais.

\section{A jurisprudência da CIDH em matéria de liberdade de expressão}

Como aponta a relatoria especial para liberdade de expressão constituída no âmbito da Organização dos Estados Americanos, ${ }^{20}$ até o final de 2011, 14 casos foram decididos pela CIDH relativamente à temática. ${ }^{21} \mathrm{Na}$ presente seção de texto, 13 casos serão considerados, eis que o caso Gomes Lund, já referido anteriormente, também integra a lista dos casos apreciados pela corte relacionados à liberdade de expressão. Essa inserção do caso Gomes Lund se relaciona ao direito de acesso à informação, tendo em vista a situação de violação experimentada pelos familiares das vítimas diante da falta de informação relativa ao desaparecimento forçado de 62 pessoas, empreendido por agentes estatais durante o regime militar brasileiro. No entanto, como visto anteriormente, as menções a julgados europeus no caso Gomes Lund não se relacionam à temática debatida nesta seção do texto.

19 Como afirma a CIDH: "Basándose en los párrafos anteriores, la Corte encuentra que hay amplia evidencia para concluir que en 1973, año de la muerte del señor Almonacid Arellano, la comisión de crímenes de lesa humanidad, incluido el asesinato ejecutado en un contexto de ataque generalizado o sistemático contra sectores de la población civil, era violatoria de una norma imperativa del derecho internacional. Dicha prohibición de cometer crímenes de lesa humanidad es una norma de ius cogens, y la penalización de estos crímenes es obligatoria conforme al derecho internacional general." (CIDH, 2006a, par. 99).

20 Página eletrônica disponível em: <http://www.oas.org/en/iachr/expression/index.asp>. Acesso em: 19 Set. 2013.

21 São eles: Caso "La Última Tentación de Cristo" (Olmedo Bustos y otros) vs. Chile (CIDH, 2001d); Caso Ivcher Bronstein vs. Perú (CIDH, 1999; 2001e); Caso Herrera Ulloa vs. Costa Rica (CIDH, 2004a); Caso Ricardo Canese vs. Paraguay (CIDH, 2004b); Caso Palamara Iribarne vs. Chile (CIDH, 2005); Caso Claude Reyes y otros vs. Chile (CIDH, 2006b); Caso Kimel vs. Argentina (CIDH, 2008); Caso Tristán Donoso vs. Panamá. (CIDH, 2009a); Caso Ríos y otros vs. Venezuela (CIDH, 2009b); Caso Perozo y otros vs. Venezuela (CIDH, 2009c); Caso Usón Ramírez vs. Venezuela (CIDH, 2009d); Caso Manuel Cepeda Vargas vs. Colombia (CIDH, 2010b); Caso Gomes Lund y otros vs. Brasil (CIDH, 2010a) e Caso Fontevecchia D'Amico vs. Argentina (CIDH, 2010c). Listagem dos casos sobre liberdade de expressão, com resumo das demandas e links para download da íntegra das decisões, disponível em: < http://www.oas.org/es/cidh/ expresion/jurisprudencia/si_decisiones_corte.asp>. Acesso em: 19 Set. 2013. 
A liberdade de pensamento e expressão está disciplinada no artigo 13 da Convenção Americana, ${ }^{22}$ o qual teria uma formulação mais ampla se comparada à formulação do artigo correspondente da Convenção Europeia de Direitos do Homem. ${ }^{23}$ De toda forma, diferentemente da jurisprudência em matéria de anistias internas, a jurisprudência em matéria de liberdade de expressão refere-se a um dispositivo específico da Convenção Americana, de maneira que a redação dada a esse artigo pelas Convenções Americana e Europeia passa a ser elemento importante para compreensão da jurisprudência das duas cortes regionais na matéria. ${ }^{24}$

Neste passo, a interpretação emprestada ao artigo 13 pela CIDH atribui à liberdade de expressão um caráter amplo e uma proteção considerada mais extensiva se comparada com outras interpretações de sistemas de tutela diversos (BURGORGUE-LARSEN; TORRES, 2011, p. 536). De uma forma geral, a corte considera que esse direito possui duas dimensões, uma coletiva e outra individual. A dimensão individual iria além do direito de falar ou escrever, compreendendo o uso de quaisquer meios apropriados à comunicação e divulgação de ideias. Do ponto de vista coletivo, incluiria a troca de ideias e informações entre seres humanos e também a comunicação de massa, de forma que todo indivíduo teria o direito de

22 "Artigo 13. Liberdade de pensamento e de expressão

1. Toda pessoa tem direito à liberdade de pensamento e de expressão. Esse direito compreende a liberdade de buscar, receber e difundir informações e idéias de toda natureza, sem consideração de fronteiras, verbalmente ou por escrito, ou em forma impressa ou artística, ou por qualquer outro processo de sua escolha.

2. O exercício do direito previsto no inciso precedente não pode estar sujeito a censura prévia, mas a responsabilidades ulteriores, que devem ser expressamente fixadas pela lei e ser necessárias para assegurar:

a. $\quad$ o respeito aos direitos ou à reputação das demais pessoas; ou

b. a proteção da segurança nacional, da ordem pública, ou da saúde ou da moral públicas.

3. Não se pode restringir o direito de expressão por vias ou meios indiretos, tais como o abuso de controles oficiais ou particulares de papel de imprensa, de freqüências radioelétricas ou de equipamentos e aparelhos usados na difusão de informação, nem por quaisquer outros meios destinados a obstar a comunicação e a circulação de idéias e opiniões.

4. A lei pode submeter os espetáculos públicos a censura prévia, com o objetivo exclusivo de regular o acesso a eles, para proteção moral da infância e da adolescência, sem prejuízo do disposto no inciso 2.

5. A lei deve proibir toda propaganda a favor da guerra, bem como toda apologia ao ódio nacional, racial ou religioso que constitua incitação à discriminação, à hostilidade, ao crime ou à violência." ORGANIZAÇÃO DOS ESTADOS AMERICANOS, 2011, p. 423).

23 "Artigo 10. Liberdade de expressão

1. Qualquer pessoa tem direito à liberdade de expressão. Este direito compreende a liberdade de opinião e a liberdade de receber ou de transmitir informações ou ideias sem que possa haver ingerência de quaisquer autoridades públicas e sem considerações de fronteiras. O presente artigo não impede que os Estados submetam as empresas de radiodifusão, de cinematografia ou de televisão a um regime de autorização prévia.

2. O exercício desta liberdades, porquanto implica deveres e responsabilidades, pode ser submetido a certas formalidades, condições, restrições ou sanções, previstas pela lei, que constituam providências necessárias, numa sociedade democrática, para a segurança nacional, a integridade territorial ou a segurança pública, a defesa da ordem e a prevenção do crime, a proteção da saúde ou da moral, a proteção da honra ou dos direitos de outrem, para impedir a divulgação de informações confidenciais, ou para garantir a autoridade e a imparcialidade do poder judicial.” (CONSELHO DA EUROPA, 1950).

24 Sobre a jurisprudência da CEDH em matéria de liberdade de expressão, ver o estudo produzido pela relatoria especial da OEA sobre o tema, disponível em: <http://www.oas.org/es/cidh/expresion/ showarticle.asp?artID=263\&IID=2>. Acesso em: 19 Set. 2013. 
receber opiniões de terceiros e de ter acesso à informação, além de poder difundir suas próprias ideias. Vale sublinhar que, segundo a corte, as duas dimensões referidas seriam interdependentes, devendo ser garantidas simultaneamente (BURGORGUELARSEN; TORRES, 2011, p. 537).

O caso Claude Reyes e outros vs. Chile inaugurou uma segunda geração de julgados relacionados à liberdade de expressão, tendo sido afirmado pela CIDH o direito específico de acesso à informação, em especial a informação pública controlada por órgãos do Estado. Por fim, para finalizar esse panorama sobre o entendimento da corte na matéria, afirma-se a possibilidade de restrições à liberdade de expressão, e a corte tem analisado em sua jurisprudência tais restrições, apresentando um entendimento convergente com a $\mathrm{CEDH}$ de que uma sociedade democrática demanda a expressão livre de ideias, tanto quanto seja possível (BURGORGUELARSEN; TORRES, 2011, p. 537).

Dentre os temas abordados pela CIDH relativamente à temática, podem ser mencionados a questão da censura prévia e a responsabilidade internacional de todos os setores do Estado, meios indiretos para violação da liberdade de expressão (exigência de nacionais para operar canais de televisão, por exemplo), difamação criminal e acesso à informação pública, como já referido (BERTONI, 2009).

Relativamente ao uso de precedentes europeus, vale mencionar, desde logo, o uso diminuído desses julgados pela $\mathrm{CIDH}$ nos casos mais recentes relacionados às violações à liberdade de expressão, o que permitiria inferir uma influência de interpretações europeias mais marcante dentre os primeiros casos analisados pela corte sobre a matéria, no início dos anos 2000. No entanto, seria possível afirmar que a jurisprudência europeia já estaria enraizada nas decisões da CIDH, de forma que as menções somente aos próprios leading cases da corte sobre liberdade de expressão, como visto nos casos mais recentes, já conteriam o teor da interpretação europeia, sem que fosse possível afirmar o fim do diálogo entre as duas cortes (BERTONI, 2009, p. 352).

Neste passo, os casos Tristán Donoso (esse, em especial, não faz qualquer menção à julgados europeus), Kimel, Ríos, Perozo, Usón Ramirez e Manuel Cepeda Vargas importam julgados europeus, mas somente casos relacionados a questões processuais, produção de provas, responsabilidade internacional dos Estados perante a convenção, uso legítimo da força pelo Estado, esgotamento recursos internos, carga da prova e competência da corte para determinar o pagamento de indenizações.

Dentre esses casos, há 6 menções a julgados europeus diretamente relacionados à questão da liberdade de expressão. Em todos a menções, trata-se de uso para legitimar a atuação da CIDH, como já visto relativamente à jurisprudência 
sobre anistias internas. Assim, o caso Usón Ramirezutiliza precedentes europeus para afirmar que restrições legítimas a direitos fundamentais são aquelas que pretendem proteger outros direitos fundamentais (CIDH, 2009d, par. 65). ${ }^{25}$ Nesse mesmo caso, a menção de que opiniões das pessoas não podem ser submetidas a requisitos de veracidade também se apoiou na menção a caso europeu (CIDH, 2009d, par. 86). ${ }^{26}$ Com base em julgado da CEDH, afirmou-se que, em uma sociedade democrática, entidades estatais estão todas expostas ao escrutínio do público e que suas atividades se inserem na esfera de debate público (CIDH, 2009d, par. 83). ${ }^{27}$ Nesse mesmo sentido, o caso Kimelmenciona a possibilidade de restrições à liberdade de expressão (CIDH, 2008, par. 78$)^{28}$ e a questão da opinião e veracidade (CIDH, 2008, par. 93). ${ }^{29}$ Por fim, o caso Manuel Cepeda Vargas refere julgado europeu para afirmar que vozes de oposição são necessárias para a sociedade democrática (CIDH, 2010b, par. 173). ${ }^{30}$

Considerando os primeiros casos proferidos pela $\mathrm{CIDH}$ na matéria, todos fizeram importação de interpretações europeias próprias à temática da liberdade de expressão - para além de questões processuais. Os casos Claude Reyes, Palamara, Ricardo Canese e Herrera Ulloa empreenderam usos semelhantes dos julgados da CEDH. Assim, no caso Claude Reyes, afirmou-se que o controle democrático, exercido por meio da opinião pública, fomenta a transparência e permite a responsabilidade dos funcionários sobre sua gestão pública (CIDH, 2006b, par. 87). ${ }^{31}$ Por seu turno, afirmou-se no caso Palamara a importância da publicidade de processos judiciais (CIDH, 2005, par. 168), ${ }^{32}$ já a importância da publicidade para os partidos e para o debate político foi ressaltada no caso Ricardo Canese (CIDH, 2004b, par. 89-

25 Nas notas de rodapé 52 a 54, a CIDH menciona os casos da CEDH Steel and Morris v. the United Kingdom, no. 68416/01, 2005-II e Kuliś and Różycki v. Poland, no. 27209/03, parágrafos 34 e 35, 2009.

26 Nas notas de rodapé 73 e 74, a CIDH menciona o caso Lingens v. Austria, julgamento de 8 de julho de 1986, parágrafo 46, Series A No. 103.

27 Na nota de rodapé 66, há menção ao caso da CEDH Castells v. Spain. judgment of 23 of April 1992, parágrafos 42 e 46. Series A no. 236 e Cumpana and Mazare v. Romania [GC], no. 33348/96, parágrafo 115, ECHR 2004-XI.

28 Na nota de rodapé 57, há menção aos casos da CEDH Castells v. Spain. judgment of 23 of April 1992, parágrafos 42 e 46. Series A no. 236 e Cumpana and Mazare v. Romania [GC], no. 33348/96, parágrafo 115, ECHR 2004-XI.

29 Na nota de rodapé 71, a CIDH menciona o caso Lingens v. Austria, julgamento de 8 de julho de 1986, parágrafo 46, Series A No. 103.

$30 \mathrm{Na}$ nota de rodapé 254, são mencionados os seguintes julgados europeus: Freedom And Democracy Party (ÖZDEP) v. Turkey, Application no. 23885/94, julgamento de 8 de dezembro de 1999, parágrafo 41 e Socialist Party and others v. Turkey, application no. 20/1997/804/1007, julgamento de 25 de Maio de 1998, parágrafo 47.

31 Na nota de rodapé 89, são citados os casos CEDH: Feldek v. Slovakia, no. 29032/95, \83, ECHR 2001-VIII e Surek and Ozdemir v. Turkey, nos. 23927/94 and 24277/94, \60, ECHR Judgment of 8 July, 1999. Nesse mesmo sentido, caso Palamara (CIDH, 2005, par. 83, nota de rodapé 181); caso Ricardo Canese (CIDH, 2004b, par. 97, nota de rodapé 130); caso Herrera (CIDH, 2004a, par. 127, nota de rodapé 105).

32 Na nota de rodapé 202, são citados os casos CEDH: Osinger v. Austria, no. 54645/00, parágrafo 44, julgamento de 24 de março de 2005; Riepan v. Austria, no. 35115/97, parágrafo 40, CEDH 2000-XII; y Tierce e outros v. San Marino, nos. 24954/94, 24971/94 e 24972/94, parágrafo 88, CEDH 2000-IX. 
90). ${ }^{33}$ As restrições à liberdade de expressão foram debatidas especialmente no caso Herrera com apoio de interpretação europeia (CIDH, 2004a, par. 120)..$^{34} \mathrm{~A}$ liberdade de expressão foi referida como pilar da sociedade democrática, com forte apelo à jurisprudência europeia nos casos Última Tentaşão de Cristo, Ivcher, Ricardo Canese e Herrea. ${ }^{35}$ Finalmente, o caso Ivcher mencionou que as ações e omissões dos Estados devem estar sujeitos ao controle da opinião pública (CIDH, 2004a, par. 155) $\cdot{ }^{36} \mathrm{Em}$ todas essas importações, o uso dos julgados europeus esteve relacionado ao objetivo maior de legitimar a interpretação da CIDH na matéria.

Por fim, vale ressaltar que o caso mais recente da corte relativamente à temática da liberdade de expressão, caso Fontevecchia, traz alguns elementos novos em relação às importações de julgados empreendidas até o momento. Tais menções ainda se constituem como forma de emprestar persuasão à interpretação da CIDH. Neste passo, a corte refere o direito à imagem no âmbito da proteção da vida privada (CIDH, 2010c, par. 49) ${ }^{37}$ a interferência abusiva e arbitrária do Estado nesse mesmo

33 Nas notas de rodapé 125 e 126, são citados os casos CEDH: Incal v. Turkey, judgment of 9 June, 1998, Reports 1998-IV, para. 46; Bowman v. The United Kingdom, julgamento de 16 de fevereiro de 1998, Reports 1998-I, para. 42.

34 Nessa decisão, são citados os seguintes casos CEDH relativos às restrições à liberdade de expressão: Sunday Times v. United Kingdom, julgamento de 29 de março de 1979, Series A no. 30, parágrafo 59; Dichand e outros v. Austria, julgamento de 26 de fevereiro de 2002, parágrafo 39; Lingens v. Austria, julgamento de 8 de julho de 1986, Series A no. 103, parágrafo 42; Castells v. Spain, julgamento de 23 de abril de 1992, parágrafos 42 e 46, Series A no. 236; Thoma v Luxemburgo, julgamento de 29 de março de 2001, parágrafo 62. Nesse mesmo sentido, caso Ricardo Canese (CIDH, 2004b, par. 102), casos CEDH Dichand e outros v. Austria, julgamento de 26 de fevereiro de 2002, parágrafo 39 e Lingens v. Austria, julgamento de 8 de julho de 1986, Series A no. 103, parágrafo 42. Caso Ivcher (CIDH, 2001e, par. 154, nota de rodapé 102), casos CEDH citados: Müller and Others judgment of 24 May 1988, Series A no. 133, parr. 32; y Eur. Court H.R., case of Sürek and Özdemir v. Turkey, judgment of 8 July 1999, párr. 57 (iii).

35 Caso Última Tentação de Cristo (CIDH, 2001d, par. 69, nota de rodapé 18), casos CEDH citados: Handyside case, julgamento de 7 de dezembro de 1976, Series A No. 24, parágrafo 49; The Sunday Times case, julgamento de 26 de abril de 1979, Series A no. 30, parágrafos 59 e 65; caso Barthold, julgamento de 25 de março de 1985, Series A no. 90, parágrafo 55; Lingens, julgamento de 8 de julho de 1986, Series A no. 103, parágrafo 41; Müller e outros, julgamento de 24 de maio de 1988, Series A no. 133, parágrafo 33 e Otto-Preminger-Institut v. Austria, julgamento de 20 de setembro de 1994, Series A no. 295-A, parágrafo 49. Nesse mesmo sentido, caso Ivcher (CIDH, 2001e, par. 152-53, nota de rodapé 100). Caso Ricardo Canese (CIDH, 2004b, par. 83, nota de rodapé 120), casos CEDH citados: Scharsach and News Verlagsgesellschaft v. Austria, no. 39394/98, S 29, ECHR 2003-XI; Perna v. Italy [GC], no.48898/98, \39, ECHR 2003-V; Dichand and others v. Austria, no. 29271/95, \37, ECHR 26 February 2002; Eur. Court H.R., Case of Lehideux and Isorni v. France, Judgment of 23 September, 1998, para. 55; Eur. Court H.R., Case of Otto-Preminger-Institut v. Austria, Judgment of 20 September, 1994, Series A no. 295-A, para. 49; Eur. Court H.R. Case of Castells v. Spain, Judgment of 23 April, 1992, Serie A. No. 236, para. 42; Eur. Court H.R. Case of Oberschlick v. Austria, Judgment of 25 April, 1991, para. 57; Eur. Court H.R., Case of Müller and Others v. Switzerland, Judgment of 24 May, 1988, Series A no. 133, para. 33; Eur. Court H.R., Case of Lingens v. Austria, Judgment of 8 July, 1986, Series A no. 103, para. 41; Eur. Court H.R., Case of Barthold v. Germany, Judgment of 25 March, 1985, Series A no. 90, para. 58; Eur. Court H.R., Case of The Sunday Times v. United Kingdom, Judgment of 29 March, 1979, Series A no. 30, para. 65; y Eur. Court H.R., Case of Handyside v. United Kingdom, Judgment of 7 December, 1976, Series A No. 24, para. 49. No mesmo sentido do caso Canese, ver Herrera (CIDH, 2004a, par. 113, nota de rodapé 91).

36 Notas de rodapé 103 e 104, caso CEDH citado: Sürek and Özdemir v. Turkey, judgment of 8 July 1999, parágrafo 60.

37 Nota de rodapé 42, caso CEDH citado: Von Hannover v. Germany, julgamento de 24 de junho de 2004, parágrafo 57. 
âmbito (CIDH, 2010c, par. 54), ${ }^{38}$ a questão da formulação de leis que tratam de restrições à liberdade de expressão $(\mathrm{CIDH}, 2010 \mathrm{c} \text {, par. } 67)^{39}$ e as restrições a esse direito (CIDH, 2010c, par. 90). ${ }^{40}$

Diante do exposto, pode-se afirmar que a jurisprudência da CIDH em matéria de liberdade de expressão buscou forte apoio em interpretações europeias, com um ímpeto talvez menos criativo se comparado à sua atuação nos casos relacionados às anistias internas. Vale ressaltar, também, que a jurisprudência da CIDH se relaciona a um dispositivo específico da Convenção Americana, variável que interfere na atividade de interpretação da corte. Assim, o uso enquanto argumento de autoridade parece ter sido preponderante nesse grupo de casos relacionados à liberdade de expressão.

\section{Considerações finais}

O presente artigo pretendeu analisar o diálogo que se estabelece entre a jurisprudência da Corte Europeia e a jurisprudência da Corte Interamericana, apresentando como foco do estudo a importação de interpretações europeias pela $\mathrm{CIDH}$, com o objetivo de fomentar o debate a respeito dos diferentes usos dos julgados da CEDH pela corte.

A hipótese levantada inicialmente parece ter sido confirmada após a análise dos dois grupos de casos selecionados, ou seja, para além de um processo mecânico de aplicação dos precedentes europeus, a corte importa interpretações da CEDH de uma forma estratégica, empreendendo sua própria leitura dos precedentes europeus, a depender dos contornos do caso que deve decidir. Ou ainda, a importação de decisões da $\mathrm{CEDH}$ é feita para legitimar a própria atuação da $\mathrm{CIDH}$.

Nos casos relacionados às anistias dos Estados partes, em que a corte optou claramente por invalidar as anistias locais e determinar a realização de julgamentos, interferindo de forma substantiva nos processos de transição democrática dos quatros Estados partes, o uso dos julgados europeus sobre crimes contra a humanidade, especialmente no caso Almonacid, teve como objetivo garantir a atuação da corte na análise de violações ocorridas em um momento em que a corte não possuía competência para tal. Aqui, a interpretação da CIDH foi além dos limites apresentados no precedente europeu, o qual afirmava que a consideração

38 Nota de rodapé 46, casos CEDH citados: Editions Plon v. France, julgamento de 18 de maio de 2004, parágrafo 42 e MGN Limited $v$ The United Kingdom, julgamento de 18 de janeiro de 2011, parágrafo 139.

39 Notas de rodapé 55 e 56, casos CEDH citados: Schussel v. Austria, julgamento admissibilidade de 21 de fevereiro de 2002, parágrafo 2 e Von Hannover v. Germany, julgamento de 24 de junho de 2004, parágrafos 50 e 59; MGN Limited v.The United Kingdom, julgamento de 18 de janeiro de 2011, parágrafo 143.

40 Nota de rodapé 66, caso CEDH citado: Tammer v. Estonia, julgamento de 6 de fevereiro de 2001, parágrafo 37 e Editions Plon v. France, julgamento de 18 de maio de 2004, parágrafo 26. 
de fatos pretéritos teria como finalidade uma melhor contextualização do caso concreto. A corte foi além dessa contextualização e qualificou a morte do senhor Almonacid como crime contra a humanidade, crime imprescritível e, portanto, restando impossível a sua anistia ou perdão.

Já nos casos relacionados à liberdade de expressão, em que há um dispositivo claro da Convenção Americana a guiar a interpretação da corte, o uso de julgados europeus buscou emprestar persuasão às decisões da CIDH, sendo possível afirmar uma certa convergência entre as manifestações das duas corte regionais de direitos humanos.

Verifica-se, assim, a complexidade nos usos dos julgados europeus pela CIDH. O processo de "fertilização cruzada" não teve como resultado único a uniformização da jurisprudência internacional em matéria de direitos humanos, ao menos se forem considerados os casos sobre anistias apreciados pela CIDH.

Relativamente à esse grupo de casos, o diálogo entre as cortes se deu de forma interessada: os pressupostos políticos relacionados à atuação da CIDH no primeiro grupo de julgados analisado, ou seja, sua preferência por julgamentos e um determinado posicionamento a respeito de como empreender processos de transição democrática no continente americano (invalidando anistias), interferiram fortemente na maneira como corte utilizou os precedentes da CEDH. Assim, enquanto processo complexo, a "fertilização cruzada" parece não tender, necessariamente, à uma uniformização das interpretações do órgão de proteção aos direitos humanos. Os projetos políticos das instituições internacionais, suas preferências, ou ainda, o chamado structural bias, ${ }^{41}$ possuem o condão de direcionar esse processo de referências cruzadas.

Diante do exposto, conclui-se que a análise da importação de precedentes europeus pela $\mathrm{CIDH}$ contribui para colocar luz na complexidade envolvida na interpretação do direito internacional dos direitos humanos. O movimento progressivo no sentido de uma uniformização da interpretação dessas regras parece ceder espaço para um diálogo estratégico entre cortes, o qual segue interesses e escolhas políticas próprios de cada instituição internacional.

41 A noção de structural bias desenvolvida por Martti Koskenniemi (2005, p. 600-615) no novo epílogo adicionado à reedição de From apology to utopia busca fortalecer a tese da indeterminação da linguagem do direito internacional com um argumento empírico: seria possível constatar a existência de preferências na prática das instituições internacionais que privilegiam determinados entendimentos de bem comum, determinados esquemas de alocação de recursos escassos, em detrimento de outros entendimentos e esquemas. Essas preferências não seriam expressamente declaradas, mas sustentadas pela prática institucional internacional de forma ideológica, ou seja, como se fossem algo natural, como uma necessidade dada a priori. No entanto, o structural bias compreende escolhas políticas institucionais, não afirmações neutras a respeito da distribuição de bens no mundo. É para essa dimensão política e contingente que Martti Koskenniemi chama a atenção dos internacionalistas ao reexaminar a questão da indeterminação no novo epílogo da referida obra. 


\section{Referências Bibliográficas}

BERTONI, Eduardo Andrés. The Inter-American Court of Human Rights and the European Court of Human Rights: a dialogue on freedom of expression standards. European Human Rights Law Review, $n$. 3, p. 332-352, 2009.

BURGORGUE-LARSEN, Laurence; TORRES, Amaya Úbeda de. The Inter-American Court of Human Rights. Case Law and Commentary. Oxford: Oxford University, 2011.

CONSELHO DA EUROPA. Convenção Europeia de Direitos do Homem (1950). Versão em português disponível em: <http://www.echr.coe.int/ECHR/EN/Header/Basic+Texts/The+Convention+and+additio nal+protocols/The+European+Convention+on+Human+Rights/>. Acesso em: 19 Set. 2013.

CORTE EuROpeiA DE DiREITOS HuMANOS. Caso Broniowski v Poland. Mérito. 22 jun. 2004. Application n. 31.433/96; Admissibilidade. 19 dez. 2002, Application n. 31.433/96. Disponível em: <http:// cmiskp.echr.coe.int/tkp197/view.asp?item=1\&portal=hbkm\&action=html\&highlight=Broniowski\&sessionid =73119780\&skin=hudoc-en $>$. Acesso em: 19 Set. 2013.

CORTE INTERAMERICANA DE DIREITOS HUMANOS, Caso Velásquez-Rodríguez Vs. Honduras. Reparações e custas. 21 jul. 1989. Série C No. 7. Disponível em: < http://www.corteidh.or.cr/index.php/es/ casos-contenciosos>. Acesso em: 19 Set. 2013.

Caso Barrios Altos Vs. Peru. Mérito. 14 mar. 2001a. Série C No. 75; Caso Barrios Altos Vs. Peru. Interpretação da sentença de mérito. 3 set. 2001b. Série C No. 83 e Caso Barrios Altos Vs. Peru. Reparações e custas. 30 nov. 2001c. Série C No. 87. Decisões disponíveis em: <http://www.corteidh.or.cr/index.php/es/ casos-contenciosos>. Acesso em: 19 Set. 2013.

Caso Almonacid-Arellano et al. Vs. Chile. Exceções preliminares, mérito, reparações e custas, 26 set. 2006a. Série C No. 154. Disponível em: <http://www.corteidh.or.cr/index.php/es/casos-contenciosos>. Acesso em: 19 Set. 2013.

Caso Gomes Lund et al. (Guerrilha do Araguaia) Vs. Brasil. Exceções preliminares, mérito, reparações e custas. 24 nov. 2010. Série C No. 219. Disponível em: <http://www.corteidh.or.cr/index.php/es/ casos-contenciosos >. Acesso em: 19 Set. 2013.

Caso Gelman Vs. Uruguai. Mérito e reparações. 24 fev. 2011. Série C No. 221. Disponível em: <http://www.corteidh.or.cr/index.php/es/casos-contenciosos>. Acesso em: 19 Set. 2013.

Caso Massacres de El Mozote e locais próximos v. El Salvador. Mérito, reparações e custas. Julgamento de 25 de Outubro de 2012. Série C No. 252, parágrafo 284. Disponível em: < http:/ / corteidh.or.cr/ docs/casos/articulos/seriec_252_esp.pdf>. Acesso em: 19 Set. 2013.

Caso "La Última Tentación de Cristo" (Olmedo Bustos y otros) vs. Chile. Mérito, reparações e custas, 5 fev. 2001d. Série C No. 73. Disponível em: <http://www.corteidh.or.cr/index.php/es/casoscontenciosos >. Acesso em: 19 Set. 2013.

Caso Ivcher Bronstein vs. Perú. Competência, 24 set. 1999, Série C No. 54 e Mérito, reparações e custas, 6 fev. 2001e. Série C No. 74. Disponível em: <http://www.corteidh.or.cr/index.php/es/casoscontenciosos>. Acesso em: 19 Set. 2013.

. Caso Herrera Ulloa vs. Costa Rica. Exceções preliminares, mérito, reparações e custas, 2 jul. $2004 a$. Série C No. 107. Disponível em: < http://www.corteidh.or.cr/index.php/es/casos-contenciosos>. Acesso em: 19 Set. 2013.

Caso Ricardo Canese vs. Paraguay. Mérito, reparações e custas, 31 ago. 2004b. Série C No. 111. Disponível em: <http://www.corteidh.or.cr/index.php/es/casos-contenciosos>. Acesso em: 19 Set. 2013. 
Caso Palamara Iribarne vs. Chile. Mérito, reparações e custas, 22 nov. 2005. Série C No. 135;

Caso Claude Reyes y otros vs. Chile. Mérito, reparações e custas, 19 set. 2006b. Série C No. 151. Disponível em: <http://www.corteidh.or.cr/index.php/es/casos-contenciosos>. Acesso em: 19 Set. 2013.

Caso Kimel vs. Argentina. Mérito, reparações e custas, 2 mai. 2008. Série C No. 177. Disponível em: <http://www.corteidh.or.cr/index.php/es/casos-contenciosos>. Acesso em: 19 Set. 2013.

Caso Tristán Donoso vs. Panamá. Exceções preliminares, mérito, reparações e custas, 27 jan. 2009 a. Série C No. 193. Disponível em: <http://www.corteidh.or.cr/index.php/es/casos-contenciosos>. Acesso em: 19 Set. 2013.

Caso Ríos y otros vs. Venezuela. Exceções preliminares, mérito, reparações e custas, 28 jan. $2009 \mathrm{~b}$. Série C No. 194. Disponível em: <http://www.corteidh.or.cr/index.php/es/casos-contenciosos>. Acesso em: 19 Set. 2013.

Caso Perozo y otros vs. Venezuela. Exceções preliminares, mérito, reparações e custas, 28 jan. 2009c. Série C No. 195. Disponível em: <http://www.corteidh.or.cr/index.php/es/casos-contenciosos>. Acesso em: 19 Set. 2013.

Caso Usón Ramírez vs. Venezuela. Exceções preliminares, mérito, reparações e custas, 28 nov. 2009d. Série C No. 207. Disponível em: <http://www.corteidh.or.cr/index.php/es/casos-contenciosos>. Acesso em: 19 Set. 2013.

Caso Manuel Cepeda Vargas vs. Colombia. Exceções preliminares, mérito, reparações e custas, 26 mai. 2010b. Série C No. 213. Disponível em: < http://www.corteidh.or.cr/index.php/es/casos-contenciosos>. Acesso em: 19 Set. 2013.

Caso Fontevecchia D’Amico vs. Argentina. Exceções preliminares, mérito, reparações e custas, 29 nov. 2010c. Série C No. 238. Disponível em: < http://www.corteidh.or.cr/index.php/es/casos-contenciosos>. Acesso em: 19 Set. 2013.

HENNEBEL, Ludovic. Les références croisées entre les juridictions internationales des droits de l’homme, 2007. Disponível em: <http://ssrn.com/abstract=1819764>. Acesso em: 19 Set. 2013.

KOSKENNIEMI, Martti. From apology to utopia: the structure of international legal argument. Reissue with new epilogue. Cambridge: Cambridge University, 2005.

NEUMAN, Gerald L. Import, export, and regional consent in the Inter-American Court of Human Rights. European Journal of International Law, Oxford, v. 19, n. 1, p. 101-123, 2008

NEUMAN, Gerald L. Talking to Ourselves. European Journal of International Law, Oxford, v. 16, n. 1, p. 139-142, 2005.

ORGANIZAÇÃO DAS NAÇÕES UNIDAS. Set of principles for the protection and promotion of human rights through action to combat impunity. (1997). Documento E/CN.4/Sub.2/1997/20/Rev.1, annex II. 2nd Oct. 1997. Disponível em: <http://www.unhchr.ch/huridocda/huridoca.nsf/\%28Symbol\%29/E. CN.4.sub.2.1997.20.Rev.1.En>. Acesso em: 19 Set. 2013.

ORGANIZAÇÃO DOS ESTADOS AMERICANOS. Convenção Americana sobre Direitos Humanos Pacto de San José da Costa Rica (1969). Legislação de direito internacional. Obra coletiva de autoria da Editora Saraiva com a colaboração de Antônio Luiz de Toledo Pinto, Márcia Cristina Vaz dos Santos Windt e Lívia Céspedes. 4. ed. São Paulo: Saraiva, 2011, p. 423. (Saraiva de Legislação).

SLAUGHTER, Anne-Marie. A Typology of Transjudicial Communication. University of Richmond Law Review, v. 29, p. 103, 1994. 
TRINDADE, Antônio Augusto Cançado. Le développement du droit international des droits de l'homme à travers l'activité et la jurisprudence des Cours Européenne et Interaméricaine des Droits de l'Homme. In: Trindade, A. A. C. A Humanização do Direito Internacional. Belo Horizonte: Del Rey, 2006.

VEÇOSO, Fabia Fernandes Carvalho; AMARAL JR., Alberto do. The Inter-American System as New Grossraum? Assessing the Case Law of the Inter-American Court of Human Rights. European Society of International Law 2011 4th Research Forum, maio 2011. Disponível em SSRN: <http://ssrn.com/ abstract $=1967666>$. Acesso em: 19 Set. 2013.

\section{Fabia Fernandes Carvalho Veçoso}

fabia.vecoso@gmail.com

Doutora e mestre em Direito Internacional pela Universidade de São Paulo. Pesquisadora Visitante no Instituto Erik Castrén de Direito Internacional e Direitos Humanos, Universidade de Helsinki, em 2011. Bolsista do Programa Jovens Líderes do Fundo Sasakawa (SYLFF) em 2011. Professora do Programa de Mestrado em Constitucionalismo e Democracia da Faculdade de Direito do Sul de Minas - Pouso Alegre/MG, Brasil. Professora do Programa de Pós-Graduação Lato Sensu da DIREITO GV (GVlaw). São Paulo/SP, Brasil. 